\title{
“A propósito da metáfora” (1975), de Luiz Antônio Marcuschi: apontamentos para uma perspectiva sociocognitiva e interacional da metaforicidade
}

\author{
Edwiges Maria Morato \\ Nathália Luiz de Freitas ${ }^{2}$
}

Resumo: Este texto tem por objetivo apontar tendências teóricas importantes para a reflexão atual sobre a metáfora anunciadas já em 1975 por Luiz Antônio Marcuschi em um ensaio intitulado "A propósito da metáfora", retomada em 200o. Dentre essas tendências, importantes para o estudo sociocognitivo do fenômeno, apontamos o papel da comparação na constituição da metáfora, a relação da metáfora com teorias do conhecimento e a identificação do escopo de compreensão da figuratividade: o uso real da linguagem e a atividade comunicativa.

Palavras-chave: Metáfora. Conhecimento. Atividade comunicativa.

\begin{abstract}
This text aims to point out important theoretical tendencies for the current reflection on the metaphor already announced in 1975 by Luiz Antônio Marcuschi in an essay titled "About the metaphor", resumed in 2000. Among these tendencies, important for the sociocognitive study of the phenomenon, we point out the role of comparison in the constitution of metaphor, the relation of metaphor to theories of knowledge and the identification of the scope of understanding of figurativeness: the real use of language and communicative activity.
\end{abstract}

Keywords: Metaphor. Knowledge. Communicative activity.

\footnotetext{
1 Professora do Departamento de Linguística do Instituto de Estudos da Linguagem/Unicamp. É líder do grupo de pesquisa COGITES - Cognição, Interação e Significação - e coordenadora do LAFAPE - Laboratório de Fonética e Psicolinguística. É Graduada em Linguística (Unicamp) e em Fonoaudiologia (PUCCAMP), mestre e doutora em Linguística pela Unicamp na área de Neurolinguística.

${ }^{2}$ Doutoranda em Linguística, subárea Neurolinguística, pela Universidade Estadual de Campinas - UNICAMP. Docente do Instituto Federal de Educação, Ciência e Tecnologia do Sul de Minas Gerais - IFSULDEMINAS - Campus Poços de Caldas.
} 
Résumé: Ce texte vise à souligner des tendances théoriques importantes pour la réflexion actuelle sur la métaphore déjà annoncée en 1975 par Luiz Antônio Marcuschi dans un essai intitulé "A propósito da metáfora", repris en 2000. Parmi ces tendances, importantes pour l'étude sociocognitive du phénomène, nous soulignons le rôle de la comparaison dans la constitution de la métaphore, la relation de la métaphore avec les théories de la connaissance, et l'identification de la prise de la compréhension de la figurativité: l'utilisation effective du langage et de l'activité communicative.

Mots-clès: Métaphore. Connaissance. Activité communicative.

\section{Introdução}

Num ensaio escrito e rescrito nos anos 1970, publicado nos anos 1980 e republicado em 200o, intitulado "A propósito da metáfora" (1975), Luiz Antônio Marcuschi aborda vários aspectos ainda hoje intrigantes a respeito do fenômeno.

Marcuschi tece nesse ensaio instigantes reflexões antes mesmo da publicação do livro seminal de Lakoff e Johnson (1980) sobre metáfora (portanto, antes da consolidação da teoria conceptual de metáfora e de seus desdobramentos), como sua relação com a criatividade enunciativa e a performatividade, com os vários tipos de conhecimento e enquadres sociocognitivos que ancoram a construção do sentido, com o contexto local e global de sua produção e interpretação. Organizado a partir da contribuição de autores "olimpicamente ignorados pelos novos 'desbravadores"' (MARCUSCHI, 200o, p. 72) da tendência conceptualista que viria a seguir, seu texto tece várias considerações cruciais para quem estuda metáfora, seja no âmbito da Teoria da Metáfora Conceptual (TMC), seja nas brechas de seus seguimentos e críticas. 
O foco de nossa atenção neste trabalho é a observação de tendências teóricas anunciadas no referido ensaio, em especial a discussão em torno da relação entre metáfora e outros processos figurativos, como a comparação.

Com efeito, são muitas as questões que ainda cercam o estudo da metáfora no campo da Linguística. Parte integrante dos domínios da Linguística que se interessam explicitamente pela cognição humana, o estudo da metaforicidade (ou da figuratividade, de um modo mais amplo) tem abrigado um conjunto expressivo de aportes teóricos e analíticos sobre os processos de significação verbais e não verbais, a construção da referência, a conceptualização, entre outros temas.

Entre as antigas questões que ainda cercam o estudo da figuratividade, encontra-se a controversa relação da metáfora com a analogia e a comparação. Além de aproximarem termos e domínios linguístico-conceptuais distintos, processos como esses atuam na construção de um terreno comum (common ground) essencial para atividades de referenciação, desenvolvimento do tópico discursivo e coesividade comunicacional. São, assim, processos importantes para o estudo da conceptualização e das relações entre linguagem e cognição.

É certo que hoje, num contexto teórico pós-Lakoff e Jonhson (1980), ao falarmos de figuratividade no campo da linguagem, dificilmente deixamos de pensar nas experiências da vida cotidiana, nas condições psicofísicas dessas experiências, na familiaridade semânticopragmática suscitada por sintagmas metafóricos e seus enquadramentos sociocognitivos, nos substratos analógicos e comparativos da figuratividade e nas regularidades linguísticas que a 
constituem e caracterizam. Porém, a antiga indagação de origem filosófica parece cercar as opções teóricas que encontramos no estudo sociocognitivo da figuratividade, encerrando velhas questões sobre as quais a TMC (LAKOFF; JOHNSON, 1980) não se furtou a falar de um modo ou de outro, como as que envolvem as relações entre o linguístico e o conceptual, entre mente e corpo, entre o verbal e o não verbal.

As relações entre metáfora e comparação, ou entre metáfora e analogia, integram as questões que estão sob a égide das relações aludidas acima. Para uns, a analogia, como a comparação, é indispensável à criação da metáfora (CORMAC, 1990). Para outros, como Perelman e Olbrechts-Tyteca (2005), por exemplo, a metáfora pode ser considerada uma analogia condensada, derivada da fusão entre o alvo e o análogo. Por seu turno, Soares da Silva (1997, p.72) afirma que

a metáfora não é uma mera extensão (ou transferência) semântica de uma categoria isolada para outra categoria de um domínio diferente, mas envolve uma analogia sistemática e coerente entre a estrutura interna de dois domínios da experiência e, consequentemente, todo o conhecimento relevante associado aos conceitos e domínios em causa.

Outros autores assinalam que a analogia, como a comparação, está contida na metáfora, atuando em sua construção como uma condição necessária, mas não suficiente (BLACK, 1993).

Ainda que haja autores que usem de maneira indistinta os termos metáfora e analogia em muitos campos do Conhecimento, grandes são 
os esforços para estabelecer diferenças entre eles (DUIT, 1991) ${ }^{3}$, ou, admitida uma semelhança, considerar que a primeira incorpora a segunda. Duit (1991, p. 651), a propósito, assim postula a diferença entre analogia e metáfora:

uma analogia compara explicitamente as estruturas de dois domínios: ela indica semelhança ou identidade de partes das estruturas. Uma metáfora, por sua vez, compara implicitamente, destacando características ou qualidades relacionais que não coincidem em dois domínios. Tomadas literalmente, as metáforas são simplesmente falsas.

Para outros autores, como Gentner (1983), a maioria das metáforas, cuja natureza relacional seria não apenas derivada de atributos compartilhados entre a fonte e o alvo, pode ser tomada como analogia. Ao se estruturarem em torno da similaridade entre domínios conceituais distintos, as analogias podem ser consideradas metáforas (VOSNIADOU, 1989).

A observação de que as analogias, ao envolverem similaridades não literais entre domínios conceptuais distintos, podem ser tomadas como metáforas, e que ambas atuam de maneira constitutiva no sistema conceptual, é assinalada por vários autores, como Lakoff (1987).

As relações entre comparação e metáfora, por seu turno, estão sob um antigo escrutínio teórico em vários domínios do Conhecimento (como a Filosofia, a Literatura, a Linguística, as Ciências Cognitivas), mas é nas chamadas teorias contemporâneas da metáfora (isto é, as que

${ }^{3}$ De acordo com Duit (1991), o que caracteriza a analogia como um modelo é a relação entre domínios diferentes (um familiar, análogo, fonte, e outro desconhecido ou alvo) na representação de uma ideia. 
partem ou levam em conta os trabalhos de Lakoff $(1987,1993)$; Lakoff e Johnson (1980), bem como toda uma linhagem que a eles se sucedeu) que certas questões emergem de forma pontual a partir da hipótese de que concebemos o mundo figurativamente e de que a metáfora é uma operação cognitiva fundamental, subjacente à linguagem e às ações humanas cotidianas.

A questão que importa destacar nesse cenário é: toda metáfora seria ou envolveria comparação? Dito de outra forma: toda comparação é metafórica? Ocupariam, ambas, lócus distintos, como linguagem e mente? Até que ponto nossa conduta ou nossa experiência psicossocial cotidiana refletiria a forma como compreendemos e produzimos comparações e metáforas em múltiplas práticas sociais e discursivas nas quais estamos imersos?

Desde que Aristóteles, na Poética, assinalou, entre as propriedades da metáfora, a transferência de significado de um termo para outro (se afirmamos, por exemplo, que "Fulana é uma flor", as características de flor serão transferidas para Fulana) e associou a comparação a formas diferentes, a discussão entre metáfora e comparação se projeta na reflexão de vários estudiosos, antes e depois da Teoria da Metáfora Conceptual (LAKOFF; JONHSON, 1980) .

Autores como Vosniadou (1989), por exemplo, discutem o fundamento das comparações, lembrando que muitos estudiosos questionam se o pertencimento a domínios conceituais iguais ou diferentes seria uma condição para a caracterização da analogia.

\footnotetext{
${ }^{4} \mathrm{Na}$ verdade, como assinalam vários autores, Aristóteles não chegou a formular propriamente uma teoria sobre metáforas.
} 
Segundo a autora, uma das condições para a comparação seria a similaridade estrutural entre domínios, sejam estes iguais ou diferentes.

Se analogia e metáfora são processos relacionados de um modo ou de outro desde a definição aristotélica de metáfora enquanto transposição de uma espécie a outra por via de analogia (ARISTÓTELES, 1999, p. 274), comparação e metáfora, por seu turno, nem sempre são tomados como processos confundíveis, apesar de serem atinentes à figuratividade (MARCUSCHI, 2000[1975]).

No campo da estilística e da gramática tradicionais, cumpre observar, as características que estão a assemelhar e a diferenciar os dois processos são conhecidas: a comparação é construída com base na aproximação entre duas coisas que têm algo em comum, isto é, uma semelhança, normalmente indicada por um termo (verbo, adjetivo, conjunção) que licencia a comparação (como, à semelhança de, tal como, ter o ar de, assim como, etc.): "Aquele homem é alto como um poste". A comparação é possível por uma semelhança entre homem e poste: ambos são altos 5 .

Também se diz aqui que a comparação, nesse caso, é do tipo motivada, uma vez que ela é explicitada no enunciado. Uma comparação é chamada de não motivada quanto o que há em comum entre duas coisas não é explicitado: "Ele parece um poste". A metáfora, por sua vez, é entendida como uma comparação explícita, uma vez que o termo de semelhança entre duas coisas não é explicitado: "Meu

\footnotetext{
${ }^{5}$ Sardinha (2007) assinala, contudo, que a comparação pode se dar entre coisas não apenas diferentes, mas similares ("O rio parecia uma cobra se arrastando na areia quente").
} 
computador é uma tartaruga". Aqui, a relação é de identificação, não de semelhança.

$\mathrm{Na}$ comparação, o ponto em comum entre duas coisas é explicitado: "Com lentidão, o computador funciona como uma tartaruga”. Quando o que é comparado (o computador) está presente, trata-se de uma metáfora de in praesentia. Quando o que está presente é apenas o que compara (tartaruga), chamamos a metáfora de in absentia: "Que tartaruga!".

A reflexão proposta por Lakoff e Johnson (1980) indica que nem todas as características de flor, no exemplo fornecido anteriormente, migrariam ou seriam transferidas para Fulana, uma vez que muitos poderiam ser os atributos indicados na relação entre flor e Fulana, a depender do contexto de produção do enunciado ou das intenções comunicativas de quem o profere: ser uma flor, desse modo, não indica apenas que Fulana é agradável, delicada, jovem, etc., podendo significar ainda que ela é virgem, infantil, nociva etc.

Com isso, uma propriedade importante da comparação, bem como da metáfora, se percebe aqui: podem ser, ambas, motivadas. São fenômenos, pois, contextual e cognitivamente investidos. A ideia de que há ganho cognitivo no uso da metáfora, recusada por Aristóteles (1999), cai por terra para os estudiosos que a tomam a partir de uma perspectiva pragmática ou (sócio)cognitiva.

Num quadro de relações de semelhanças e diferenças, metáfora e comparação (assim como processos analógicos) parecem essenciais à construção da conceptualização e à constituição da cognição humana de uma maneira geral; têm um papel crucial na percepção de 
similaridade entre as coisas, na perspectivação conceitual em distintos contextos, na categorização, na compreensão e organização de padrões relacionais e na predicação figurativa de nossas experiências socioculturais (SOLOMON, 1986).

\section{Comparação, Metáfora, Conhecimento}

Em função dos nossos objetivos, que é trazer a reflexão sobre metáfora e comparação na construção do sentido a partir do ensaio de Marcuschi (2000 [1975]), vejamos de forma esquemática algumas considerações extraídas do referido texto, escrito bem antes da publicação de Lakoff e Johnson (1980). Seguimos, aqui, a tese do autor, segundo a qual a figuratividade deve ser compreendida numa perspectiva interacional e no âmbito da teoria do Conhecimento. Lembramos as premissas dessa perspectiva, esboçadas pelos dois autores com os quais Marcuschi (2000 [1975]) trabalha em seu ensaio, Richards e Black. Para Richards, como assinala Contenças (1999, p. 49): "na metáfora não há simples deslocamento de palavras, mas, uma transferência de contextos, esquemas, de quadros conceptuais, de categorias”. Com base na Teoria Interacional da Metáfora, Marcuschi (200o [1975]) assim reúne as características do fenômeno:

(i) a metáfora serve de meio para aferir a capacidade criativa natural do homem;

(ii) a metáfora é um fenômeno que se situa nos limites do dizível dentro da esfera linguística;

(iii) a metáfora é um modo específico de conhecer o mundo, que, ao lado do conhecimento lógico-racional, tem sua razão 
de ser e instaura uma série de valores de outra maneira perdidos ou não-encontrados;

(iv) a metáfora é um modo novo de conhecer e comunicar o mundo assim conhecido. Ela é, de certa forma, um recurso reestruturador da realidade, criando novas áreas de experiência que fogem ao indivíduo restrito à realidade puramente factual.

(v) nos fundamentos da metáfora estão bases da experiência empírica que a consciência acumulada reserva para elaborar estruturas e universos além da própria experiência (p. 76).

No tocante às relações entre metáfora e comparação, Marcuschi (2000 [1975]) faz frente ao legado aristotélico, propondo a substituição das noções de transposição e de comparação pela de composição e de criação (numa acepção distinta a da criatividade chomskiana) ${ }^{6}$.

Lembramos, neste ponto, que a ideia de metáfora como criação aparece também na perspectiva cognitiva da metáfora pós-Lakoff e Johnson (1980). Vereza (2012, p. 50), por exemplo, afirma que a metáfora "não pressuporia uma similaridade necessariamente préexistente entre o alvo e a fonte; ela criaria cognitivamente essa similaridade".

Para a construção desse posicionamento, Marcuschi (2000 [1975]) trabalha com autores como Max Black e I. A. Richards, que seguem um caminho alternativo ao da transposição no estudo do fenômeno, chegando à proposição de uma teoria interacional (BLACK, 1962, p. 2547) ${ }^{7}$. Contudo, apesar de configurar uma perspectiva teórica que

\footnotetext{
${ }^{6}$ Marcuschi contrapõe-se à noção chomskiana de criatividade nos seguintes termos: "Daí resulta em parte a pobreza da noção de criatividade em Chomsky, que basicamente se reduz ou equivale a um processo de recursividade. Mas a criatividade parece ser algo mais do que um conjunto de regras projetivas de caráter recursivo: linguagem é algo mais do que um simples cálculo. Criar, em linguagem, é algo mais do que produzir sentenças com base numa série de regras" (MARCUSCHI, 2000 [1975], p. 73).

${ }^{7}$ Segundo essa perspectiva, a similaridade entre os termos deriva da interação entre o tópico e o veículo.
} 
pavimenta a teoria conceptual da metáfora que seria conhecida nos anos 1980, ela não chega, como bem observa Marcuschi (2000 [1975], p. 82), a repensar a comparação: “[...] a nosso ver, apesar de salvar-se da transposição, ele cai de certo modo na comparação (analogia como base)".

Uma das teses centrais defendidas no referido ensaio de Marcuschi é que

A metáfora não é fruto da comparação, e sim, no máximo, base para uma comparação a posteriori. A ordem psicológica tem aqui prioridade sobre a ordem lógica. É a metáfora que funda a comparação e não o contrário (MARCUSCHI, 200o, p. 77).

Na esteira da superação da ideia aristotélica de transposição de sentido, Marcuschi (2000 [1975]) defende que se ultrapasse a tese da comparação como fonte da metáfora, ou da tese da metáfora tomada como comparação, introduzida por Marco Fábio Quintiliano nas Institutiones Oratoriae. Se para Aristóteles, a metáfora incorpora a comparação (sendo, pois, a esta superior em termos estilísticos), para Quintiliano, a comparação incorpora a metáfora, constituindo-se em um método retórico mais amplo.

Vigorando até os nossos dias, a polêmica em torno da relação entre comparação e metáfora não tem deixado de indicar uma pequena vantagem para a metáfora, identificada já a partir do século XVII, quando se dá a esse tropo uma certa superioridade retórica (CARVALHO, 2007, p. 8o). 
Em seu estudo da semântica da metáfora, Carvalho (2007) lembra que, na tradição helênica, a metáfora e a comparação como que se confundiam, na medida que ambas levam em conta um mesmo ponto de partida elocutivo. O que poderia diferenciá-las é o traço comparativo e a coexistência verbal de dois termos. Além disso, a forma predicativa da metáfora - "isto é aquilo - lhe daria maior poder persuasivo" (CARVALHO, 2007, p. 80), a tornaria mais ardilosa e mais artificial que a comparação. Como afirma Hansen (1986, p. 19), a propósito dessa discussão: “a comparação é o desnudamento do processo, pois evidencia o procedimento enquanto o constrói”. Ao tomar a aproximação entre domínios diferentes algo natural, a metáfora parece mais convincente e credível (HANSEN, 1986, p. 21).

Parcimonioso, Marcuschi (2000 [1975]) pondera que é difícil desvincular a ideia de comparação à de metáfora, por ser a primeira uma das bases da segunda. Assim, ele pondera: "cremos que não é possível afirmar que todas as metáforas têm base na comparação" (MARCUSCHI, 2000 [1975], p. 84). A rigor, a comparação, uma "forma de violação da metáfora", afirma Marcuschi (200o [1975], p. 86), não é metáfora no sentido estrito do termo.

Em seu ensaio, Marcuschi (2000 [1975]) postula que o conhecimento criado pela metáfora não se baseia (apenas) na comparação. Sendo a metáfora de ordem "intuitiva”, antes mesmo de ser um resultado da comparação, ela a constrói e produz, ou seja, "não a formula simplesmente" (MARCUSCHI, 2000 [1975], p. 85).

A superioridade da metáfora é uma tese aristotélica retomada pelos estudos (sócio)cognitivistas, como é possível entrever na obra de Lakof 
e Johnson (1980) e mesmo no período posterior a ela. Vejamos o exemplo de Marcuschi (2000 [1975], p. 85) para ilustrar a tese de que a comparação é, "no máximo" um "resultado da metáfora e não o contrário":

\begin{abstract}
Quando ouvimos uma expressão metafórica tão corriqueira como "o dia está triste", não se dá primeiro uma comparação e então surge a metáfora. É precisamente o contrário; a comparação é um fenômeno post festum. Atribuir ao dia uma propriedade antropomórfica é produto de uma intuição cognitiva que nos leva a interpretar uma comparação. De resto, o tertium comparationis da equação não é tão facilmente encontrável, ao nível racional-lógico, pois o homem fica triste de outra forma que o dia. Basicamente, é um sistema cognoscitivo que entra em ação (p. 85-86).
\end{abstract}

Um dos desafios centrais aventados por Marcuschi (2000 [1975]) no ensaio aqui mencionado diz respeito à experiência criada pelo ato criativo da metáfora: como essa experiência se constitui, pergunta o autor? Para o autor, o caráter criativo da metáfora não se vincula apenas ao caráter criativo da língua (uma tese chomskiana), mas dos fatores internos e externos a ela que constituem a cognição humana (cognição social).

\title{
Apontamentos de Marcuschi frente os estudos contemporâneos sobre metáfora
}

A partir de orientações teórico-metodológicas que vão desde um cognitivismo mais clássico (LAKOFF; JOHNSON, 1980; LAKOFF, 1987; LAKOFF; TURNER, 1989), passando por abordagens de cunho experiencialista (GRADY, 1997; LAKOFF; JOHNSON, 1999), até perspectivas ancoradas em fatores socioculturais, pragmáticos e multimodais (STEEN, 2011; KOVECSES, 2005; SEMINO, 2008; GIBBS, 
2011; CAMERON, 2007; CHARTERIS-BLACK, 2004; VEREZA, 2010, 2013; CAMERON; DEIGNAN, 2006; FORCEVILLE, 2006, 2010), os estudos recentes compartilham a premissa de que a metáfora é fundamental ao conhecimento e à compreensão do mundo.

Dentro dessa conjuntura é que podemos notar a contemporaneidade dos escritos de Luiz Antônio Marcuschi, como o que abordamos aqui. Ao postular que "a metáfora não é fruto da comparação, e sim, no máximo, base para uma comparação a posteriori”, Marcuschi (200o [1975], p. 77) admite que o primeiro fenômeno tem primazia sobre o segundo, posição que assinala o caráter metafórico da cognição humana, tese defendida e profundada pela TMC em $1980^{8}$.

Outro ponto importante abordado por Marcuschi (2000 [1975]) em seu ensaio diz respeito às funções atribuídas à linguagem e à cognição diante da constituição metafórica. Trata-se, inclusive, de uma questão posta por diferentes pesquisadores no período pós-Lakoff e Jonhson (1980), traduzida nas críticas e desdobramentos da TMC. Vejamos, ainda que brevemente, alguns dos termos pelos quais estes se colocam.

Como assinalam diversos estudiosos do fenômeno metafórico, em especial os que levam em conta a TMC, o princípio de que a metáfora seria essencialmente constituída no/pelo pensamento e não na/pela linguagem é um dos mais combatidos nas pesquisas desenvolvidas mais recentemente (SILVA; LEITE, 2015; VEREZA, 2010; MOURA 2008).

\footnotetext{
8 Lembramos que o ensaio de Marcuschi aqui focalizado foi publicado pela primeira vez em 1975 , cinco anos antes da publicação de Metaphors We Live Be, em 1980.
} 
Além de aprofundar a dicotomia entre cognição e linguagem como se esta não fosse uma das formas de ser daquela (TOMASELLO, 1999) -, tal princípio aparta a metaforicidade do próprio funcionamento do discurso. Ao tratarem do que denominam de os "novos rumos complementares na abordagem cognitiva da metáfora", Soares da Silva e Leite (2015, p. 7-8) assinalam que:

a metáfora não é apenas um fenômeno do pensamento e da linguagem, mas é também um fenômeno da comunicação, sendo o discurso verbal ou não-verbal ou ainda o discurso multimodal o seu lugar mais natural, donde passar-se da metáfora no pensamento para a metáfora no pensamento e no discurso.

No entanto, já em 1975, Marcuschi chamava a atenção para essa questão ao indicar a finalidade de seu ensaio, que é propor uma revisão da concepção de linguagem adotada tradicionalmente para analisar a metáfora. Nas palavras do autor:

O intuito do presente ensaio é mostrar a metáfora como algo mais do que um simples fenômeno linguístico de natureza semântica. Será feita a tentativa de deslocar a metáfora da esfera puramente semântica para a área da teoria do conhecimento. De resto, a metáfora é aqui tomada como um fenômeno que se situa nos limites do dizível dentro da esfera linguística. Propor-se uma análise da metáfora nesses termos implica rever alguns aspectos da concepção de linguagem hoje vigente. Em primeiro lugar, tomando a linguagem como fenômeno social, caracteriza- se apenas um de seus lados, ou seja, seu caráter institucional, e pressupõe-se que o uso linguístico seja constantemente submetido ao consumo da comunidade. Na medida em que o uso se dá como fruto da interação consensual, ele se transforma em regra ou esquema recorrente. Regra é aqui tomada na acepção wittgensteiniana de esquema para alguma ação e por isso mesmo como estrutura pragmática (MARCUSCHI, 2000 [1975], p. 3). 
Se para Lakoff e Jonhson (1980), o lócus da metáfora é o pensamento (VEREZA, 2010), tendo a linguagem o papel de externalizar os conceitos metafóricos, na perspectiva de Marcuschi (2000 [1975]), tal fenômeno não se reduz a um caráter psico-instrumental do sistema semântico; antes, constitui-se "nos limites do dizível dentro da esfera linguística" (2000 [1975], p. 73) e faz parte dos processos associados à construção do conhecimento. Logo, na visão do autor, a metaforicidade envolve o que é da língua - como sistema e como atividade (atividade criativa), e o que é da cognição (pragmática e socioculturalmente modulada).

Além disso, Marcuschi (200o [1975]) atenta para o caráter discursivo da metáfora ao propor a revisão da concepção tradicional de linguagem então adotada em sua análise. Para o autor, se a linguagem é um fenômeno social, portanto, de ordem institucional, o uso, mediado por regras tácitas e desenvolvido nas diversas práticas discursivas, figura como um fator essencial para a compreensão da metáfora. Dessa forma, é no uso, ou seja, nas atividades discursivas cotidianas, que os esquemas de ação e pensamento são configurados e objetivados - o que compreende também o processamento metafórico.

É a partir do final dos anos de 1990 que críticos da TMC, tais como Cameron (1999), Deignan (2005) e Vereza (2008), por exemplo, reivindicam a consideração efetiva do discurso para o entendimento do fenômeno metafórico. Entre as proposições de destaque está a análise de dados autênticos ou exemplares reais de metáforas efetivamente usadas por falantes em diferentes situações discursivas, o que envolve a 
abordagem de variados gêneros textuais e dimensões sociopolíticas (CHARTERIS-BLACK, 2004).

Muitas das categorias com as quais trabalham mais recentemente os estudiosos da metáfora na perspectiva do uso sociointeracional da linguagem (tais como metaforema (CAMERON; DEIGNAN, 2006) nicho metafórico (VEREZA, 2013), metáforas sistemáticas (CAMERON; MASLEY, 2010), metáforas sistemáticas (VEREZA, 2013) etc.) derivam de críticas aos limites do conceptualismo da TMC, bem como do desenvolvimento de uma visão mais integrativa e sociocognitiva da metáfora explorada de forma mais sistemática num domínio empírico constituído de corpora autênticos e variados cujos objetos de análise são em geral fenômenos e questões socialmente relevantes.

\section{Contribuições da reflexão de Marcuschi ao estudo sociocognitivo da metáfora}

Marcuschi (2000 [1975]) aponta em seu ensaio alguns movimentos que ainda estão a exigir contornos mais definidos. Entre elas podemos apontar a possibilidade de a metáfora ser ou não explicada no contexto de teorias do conhecimento. Marcuschi (2000 [1975]) não é muito assertivo quanto a essa possibilidade de forma mais específica. Contudo, se pudermos entender enquanto "teorias do conhecimento" os modelos ou construtos elaborados no âmbito dos estudos sociocognitivistas, como a TMC (LAKOFF; JOHNSON, 1980), os Modelos Cognitivos Idealizados (LAKOFF, 1987), as teorias culturais, dinâmicas e discursivas de frame (GOFFMAN, 1974; TANNEN; 
WALLAT, 1998), os modelos de contexto (VAN DIJK, 2008, 2014) ou a teoria da mesclagem (FAUCONNIER; TURNER, 2002), o caminho iniciado por Marcuschi (200o [1975]) em seu ensaio ainda é longo e, certamente, instigante.

Quanto à discussão sobre a relação entre metáfora e comparação tratada pelo autor, de maneira mais específica, vale ressaltar que seu posicionamento salienta a natureza interacional, sociocognitiva e discursiva do fenômeno metafórico. Para Marcuschi (2000 [1975]), a primazia da metáfora tem objetivos claros: salientar o caráter criativo não da língua em si, mas do trabalho dos falantes em interação sobre ela e sua forma de interpretar e construir a realidade. É daí que nasceria a metáfora, mais da imaginação do que de uma lógica apriorística aos usos da linguagem ou das relações que eles permitem.

Como afirma Marcuschi (200o [1975]), a metáfora não é fruto da comparação; antes, ela a antecede e é em relação a ela superior, no sentido em que a constitui ("funda”, afirma o autor)9. É a primazia de uma "lógica da linguagem" sobre uma "lógica na linguagem" (ou uma lógica apriorística que encontra na linguagem o seu lugar). Não é à toa que Marcuschi (200o [1975]) afirma, com base na alusão aos elementos de conexão que estruturam a comparação (como tal qual, parecia etc.), que eles tornam o fenômeno um "ladrão de metáfora": "ele tira a força

\footnotetext{
${ }^{9}$ Vale retomar aqui o exemplo fornecido pelo autor, bem como sua análise: "Quando ouvimos uma expressão metafórica tão corriqueira como "o dia está triste", não se dá primeiro uma comparação e então surge a metáfora. É precisamente o contrário; a comparação é um fenômeno post festum. Atribuir ao dia uma propriedade antropomórfica é produto de uma intuição cognitiva que nos leva a interpretar uma comparação. De resto, o tertium comparationis da equação não é tão facilmente encontrável, ao nível racional-lógico, pois o homem fica triste de outra forma que o dia. Basicamente, é um sistema cognoscitivo que entra em ação e não uma atividade lógica (MARCUSCHI, 2000 [1975], p. 85).
} 
da metáfora e cria um símile com certa força expressiva, mas não é metáfora no sentido estrito do termo" (MARCUSCHI, 2000 [1975], p. 84). A contundência da afirmação do autor está em sua preocupação de apontar o fenômeno metafórico como sociocognitivamente motivado, o que emprestaria força à recusa de ver a metáfora, atinente à criação de universos novos, como redutível ao âmbito linguístico ou "abarcável com postulados de interpretação lógica" (MARCUSCHI, 2000 [1975], p. 85). As atuais teorizações sobre a metáfora poderiam significar uma extensão dessa preocupação de Marcuschi (2000 [1975]) em prover uma explicação não logicista ou logocêntrica para o fenômeno.

Finalmente, vale destacar outro posicionamento do autor no ensaio que ora revisitamos: o que identifica o lócus por excelência de emergência da metáfora e de seu estudo não é a língua stricto sensu, ou o sistema semântico, ou uma mente "descarnada do usuário" (SALOMÃO, 1999). O lócus da metáfora está na atividade comunicativa, no uso real da linguagem. Nesse texto de 1975, Marcuschi preconiza que o estudo da metaforicidade só faz sentido numa perspectiva não-correspondentista da relação entre linguagem e cognição.

\section{Referências}

ARISTÓTELES. Poética. São Paulo: Nova Cultural, 1999.

ARISTÓTELES. Retórica. Lisboa: Imprensa Nacional-Casa da Moeda, 2005. BERBER SARDINHA, T. Metáfora. São Paulo: Parábola, 2007.

BLACK, M. Metaphor. In: MODELS and metaphor. Ithaca: Cornell University Press, 1962. cap. 3. 
BLACK, M. More About Metaphor. In: ORTONY, A. (Ed). Metaphor and Thought. New York: Cambridge University Press, 1993.

CAMERON, L. Identifying and describing metaphor in spoken discourse data. In: CAMERON, L.; LOW, G. Researching and applying metaphor. Cambridge: Cambridge University Press, 1999.

CAMERON, L. Confrontation or complementarity? Metaphor in language and cognitive metaphor theory. Annual Review of Cognitive Linguistics, v. 5, p. 107136, 2007.

CAMERON, L.; DEIGNAN, A. The emergence of metaphor in discourse. Applied Linguistics, v. 4, n. 27, p. 671-690, 2006.

CAMERON, L.; MASLEN, R. (Orgs.). Metaphor analysis: research practice in applied linguistics, social sciences and the humanities. Londres: Equinox, 2010. CARVAlHO, M. S. F. Poesia de agudeza em Portugal. São Paulo: Edusp, 2007. CHARTERIS-BLACK, J. Corpus Approaches to Critical Metaphor Analysis. Basingstoke: Palgrave, 2004.

CONTENÇAS, P. A eficácia da metáfora na produção da ciência - o caso da genética. Lisboa. Instituto Piaget, 1999.

CORMAC. M. A Cognitive Theory of Metaphor. MIT Press, Cambridge, 1990. DEIGNAN, A. Metaphor and Corpus Linguistics. Amsterdam: John Benjamins, 2005 .

DUIT, R. On the role of analogies and metaphors in learning science. Science Education, v. 75, n. 6, p. 649-672, 1991.

FAUCONNIER, G.; TURNER, M. The way we think: conceptual blending and the mind's hidden complexities. New York: Basic Books, 2002.

FORCEVILLE, C. Non-verbal and multimodal metaphor in a cognitivist framework: agendas for research. In: KRISTIANSEN, G. et al. (Eds.), Cognitive Linguistics: Current Applications and Future Perspectives. Berlin; New York: Mouton de Gruyter, 2006. p. 379-402.

FORCEVILLE, C. Why and how study metaphor, metonymy, and other tropes in multimodal discourse? In: SOARES DA SILVA, A. et al (Eds.). Comunicação, 
Cognição e Media. Braga: Aletheia, Publicações da Faculdade de Filosofia da Universidade Católica Portuguesa, 2010. p. 41-6o.

GENTNER, D. Structure-mapping: a theoretical framework for analogy. Cognitive Science, v. 7., p. 155-170, 1983.

GENTNER, D. The mechanisms of analogical learning. In: VOSNIADOU, S.;

ORTONY, A. (Eds.). Similarity and analogical reasoning. Cambridge: Cambridge University Press, 1989. p. 199-241.

GIBBS, R. W. Evaluating conceptual metaphor theory. Discourse Processes, v. 48, n. 8, p. 529-562, 2011.

GOFFMAN, E. Frame analysis. New York: Harper \& Row, 1974.

GRADY, J. E. Foundations of meaning: primary metaphors and primary scenes.

Tese PhD. University of California at Berkley, Departament of Linguistics, Berkley, 1997.

HANSEN, J. A. Alegoria: construção e interpretação da metáfora. São Paulo: Atual, 1986.

KÖVECSES, Z. Metaphor: a practical introduction. New York: Oxford, 2002.

KÖVECSES, Z. Metaphor in Culture. Universality and Variation. Oxford: Oxford University Press, 2005.

LAKOFF, G. Women, fire and dangerous things: what categories reveal about the mind. Chicago: The University of Chicago Press, 1987.

LAKOFF, G.; TURNER, M. More than cool reason: a field guide to poetic metaphor. Chicago: The University of Chicago Press, 1989.

LAKOFF, G. The contemporary theory of metaphor. In: ORTONY, A. (Ed.).

Metaphor and Thought. New York: Cambridge University Press, 1993.

LAKOFF, G. Philosophy in the Flesh. New York: Basic Books, 1999.

LAKOFF, G.; JOHNSON, M. Metáforas da vida cotidiana. Campinas: Mercado de Letras; São Paulo: Educ, 2002.

LAKOFF, G.; JOHNSON, M. Metaphors we live by. Chicago: The University of Chicago Press, 1980.

MARCUSCHI, L. A. A propósito da metáfora. Revista de Estudos da Linguagem, Belo Horizonte, v. 9, n. 1, p. 71-89, 2000 [1975]. 
MOURA, H. M. M. Desfazendo dicotomias em trono da metáfora. Revista de Estudos da Linguagem. Belo Horizonte, v. 16, n. 1, p. 179-200, 2008.

OLBRECHTS-TYTECA, L.; PERELMAN, C. Os âmbitos da argumentação. In: OLBRECHTS-TYTECA, L.; PERELMAN, C. Tratado da argumentação: a nova retórica. São Paulo: Martins Fontes, 1996.

ORTONY, A. (Ed.). Metaphor and thought. New York: Cambridge, 1993.

PERELMAN, C. OLBRECHTS-TYTECA, L. Tratado da Argumentação: a nova retórica. 2. ed. Trad. de Maria Ermantina Galvão G. Pereira. São Paulo: Martins Fontes, 2005 .

RICHARDS, I. A. The Philosophy of Rhetoric. New York and London: Oxford University Press, 1936.

SALOMÃO, M. M. M. A questão da construção do sentido e a revisão da agenda dos estudos da linguagem. Veredas ,v. 4, p. 61-79, 1999.

SOLOMON J. Children's explanations. Oxford Review of Education. v. 12, n. 1, p. 41-51, 1986.

SEMINO, E. Metaphor in Discourse. Cambridge: Cambridge University Press, 2008.

SOARES DA SILVA, A.; LEITE, J. E. R. (Orgs.). 35 anos de Metáforas da Vida Cotidiana: Edição Temática da Revista Investigações - Linguística, Programa de Pós-graduação em Letras da Universidade Federal de Pernambuco. Recife, Brasil: Universidade Federal de Pernambuco, 2015.

SOARES DA SILVA, A. A linguística cognitiva - Uma breve introdução a um novo paradigma em linguística. Revista Portuguesa de Humanidades, v. 1, n. 1-2, p. 59-101, 1997.

STEEN, G. J. The Contemporary Theory of Metaphor - Now new and improved! Review of Cognitive Linguistics. v. 9, n. 1, p. 26-64, 2011.

TANNEN, D.; WALLAT, C. Enquadres interativos e esquemas de conhecimento em Interação: Exemplos de um exame/consulta médica. In: RIBEIRO, B.; GARCEZ, P. (Org.). Sociolingüística Interacional. Porto Alegre: Age, 1998.

TOMASELLO, M. Origens culturais da aquisição do conhecimento humano. São Paulo: Martins Fontes, 2003 (1999). 
VAN DIJK, T. A. Context and language. Discourse and context: a socio-cognitive approach. Cambridge University Press. 2008.

VAN DIJK, T. Ad. Discourse and Knowledge - a sociocognitive approach. Cambridge: Cambridge University Press, 2014. v. 1.

VEREZA, S. C. Exploring metaphors in corpora: a study of 'war' in corpus generated data In: ZANOTTO, M. S. et al. Confronting metaphor in use: an applied linguistic approach. Amsterdam: J. Benjamins, 2008. p. 163-178.

VEREZA, S. C. O lócus da metáfora: linguagem, pensamento e discurso. Cadernos de Letras da UFF, n. 41, p. 199-212, 2010.

VEREZA, S. C. (Org.). Sob a ótica da Metáfora: tempo, conhecimento e guerra.

Niterói: Editora da UFF, 2012.

VEREZA, S. C. Entrelaçando frames: a construção do sentido metafórico na linguagem em uso. Cadernos de Estudos Linguísticos, n. 1, v. 55, p. 109-25, 2013. VOSNIADOU, S. Analogical reasoning as a mechanism in knowledge acquisition: a developmental perspective. In: VOSNIADOU, S.; ORTONY, A. (Eds.). Similarity and Analogical Reasoning. Cambridge: Cambridge University Press, 1989. p. 413437.

VOSNIADOU, S.; ORTONY, A. Similarity and analogical reasoning: a synthesis. In: VOSNIADOU, S.; ORTONY, A. (Eds.). Similarity and analogical reasoning. Cambridge: Cambridge University Press, 1989. p. 199-241.

Recebido em 03/12/2017.

Aprovado em 22/12/2017. 